\title{
APPLICATION OF HPLC-DAD TECHNIQUE FOR DETERMINATION OF PHENOLIC COMPOUNDS IN BEE POLLEN LOADS
}

\author{
Ewa Waś \\ Teresa Szczęsna \\ Helena Rybak-Chmielewska \\ Dariusz Teper \\ Katarzyna Jaśkiewicz \\ Research Institute of Horticulture, Apiculture Division, Kazimierska 2, 24-100 \\ Puławy, Poland \\ *corresponding author: ewa.was@inhort.pl \\ Received: 22 December 2016; accepted: 29 April 2016
}

A bstract

A method was elaborated to determine phenolic compounds (vanillin, caffeic, p-coumaric and salicylic acids, and flavonoids: rutin, hesperetin, quercetin, pinocembrin, apigenin, kaempferol, isorhamnetin, chrysin, and acacetin) in bee pollen loads using highperformance liquid chromatography with a diode array detector (HPLC-DAD). Phenolic compounds from bee pollen were isolated on Cleanert C18-SPE columns $(500 \mathrm{mg} / 6 \mathrm{~mL}$, Agela Technologies). Polyphenols were identified by comparing the retention times and spectra of compounds found in pollen load samples with the ones of the standard mixture. Quantitative analysis was conducted using the external standard method. In addition, basic validation parameters for the method were determined. For the identified compounds (except for the salicylic acid), satisfactory (20.997) linear correlations were obtained. The elaborated method showed high repeatability and inter-laboratory reproducibility. Variability coeffcients of the majority of phenolic compounds did not exceed $10 \%$ in conditions of repeatability and inter-laboratory reproducibility, and for the total polyphenolic content they were 1.7 and $5.1 \%$, respectively. The pollen load samples $(n=15)$ differed in qualitative and quantitative composition of the phenolic compounds. In all the samples, we identified the p-coumaric and salicylic acids and flavonoids rutin, hesperetin, and apigenin nevertheless, these compounds' contents significantly differed among individual samples. The total phenolic content in the tested samples of pollen loads ranged from 0.653 to $5.966 \mathrm{mg} / 100 \mathrm{~g}$ (on average $2.737 \mathrm{mg} / 100 \mathrm{~g}$ ).

Keywords: bee pollen, flavonoids, phenols, phenolic acid, HPLC-DAD

\section{INTRODUCTION}

Polyphenolic compounds, including flavonoids, occur widely in plants but are not synthesised by humans and animals (Cook \& Samman, 1996). In recent years there has been an increased interest in studies on the positive influence of these compounds on human health, and so new sources of polyphenols in daily nutrition are being explored (Cook \& Samman, 1996; Yao et al., 2004).

Bee pollen contains an estimated 2 to $5 \%$ of polyphenols, including polyphenolic acid and flavonoid derivatives (Campos et al., 1997, 2002, 2008) and has become the subject of studies as a potential source of polyphenols (AlmarazAbarca et al., 2004). The majority of them have indicated a interdependence of the content of phenolic compounds in bee pollen and its antioxidative properties (Kroyer \& Hegedus, 2001; Almaraz-Abarca et al., 2004, 2007; Carpes et al., 2007, 2009; LeBlanc et al., 2009; Leja et al., 2007; Šarić et al., 2009; Graikou et al., 2011; Freire et al., 2012; Ulusoy \& Kolayli, 2013). The presence of polyphenolic compounds positively influence the human organism as they show, among others, anti-inflammatory, antivirus, antibacterial and antifungal properties. Thanks to their capability of capturing or inhibiting the creation of free radicals, they also have 
antioxidative properties and delay the ageing process. Bee pollen is recommended not only as a dietary supplement but also as a prophylactic and treatment of cardiovascular system diseases, allergies, infections, inflammations, gastrointestinal complaints, autoimmune system impairment, age-related diseases, cancers, etc. (Carpes et al., 2007, 2009; Šarić et al., 2009; Graikou et al., 2011; Ulusoy \& Kolayli, 2013; Omnia, Nabila \& Nadia, 2014).

Due to these beneficial properties of phenolic compounds, numerous studies have been undertaken concerning their composition in pollen loads. Most of them describe the use of the high-performance liquid chromatography with a diode array detector (HPLC-DAD) just for qualitative analysis of phenolic compounds (Markham \& Campos, 1996; Campos et al., 1997; Campos, Webby, \& Markham, 2002; AlmarazAbarca et al., 2004, 2007, 2008; Freire et al., 2012; Lv et al., 2015). The high correlation between the antioxidative properties and the content of phenolic compounds suggests the quantitative analysis of these compounds to be equally important. The analysis of total polyphenolic content commonly utilises the spectrophotometric method with Folin-Ciocalteau reagent (Carpes et al., 2007, 2009; LeBlanc et al., 2009; Mărghitaș et al., 2009; Graikou et al., 2011; Freire et al., 2012; Prelipcean, 2012; Ulusoy \& Kolayli, 2013), which was also used in Polish research on the efficiency of different methods of extraction of these compounds and on storing conditions of bee pollen loads extracts (Rzepecka-Stojko et al., 2010, 2012).

The composition of phenolic compounds in bee pollen collected under Polish pollen flow conditions has not been well recognised due to a lack of data concerning qualitative and quantitative composition. Chromatographic methods have not been used in Poland for this purpose, so the aim of our study was to develop a chromatographic method (HPLC-DAD) for the determination of polyphenolic acids and flavonoids in bee pollen loads.

\section{MATERIAL AND METHODS}

\section{Chemicals}

Reagents used as standards, vanillin ( $298.5 \%)$, p-coumaric ( $(298.0 \%)$ and salicylic acids (⒐99\%), quercetin ( $(295 \%)$, kaempferol ( $\geq 97.0 \%)$, isorhamnetin ( $295.0 \%)$ and acacetin ( $297.0 \%)$ were purchased from Sigma-Aldrich (Saint Louis, USA), while caffeic acid ( $299.0 \%)$, rutin ( $290.0 \%)$, hesperetin ( $298.0 \%)$, pinocem-

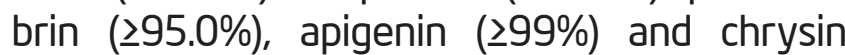
(⒐08\%) were purchased from Fluka (Buchs, Switzerland). J.T. Baker (Deventer, Holland) supplied methanol and Sigma-Aldrich (Saint Louis, USA) formic acid. Potassium hexacyanoferrate (II) $-\mathrm{K}_{4} \mathrm{Fe}(\mathrm{CN})_{6} \times 3 \mathrm{H}_{2} \mathrm{O}$ and zinc acetate - $\mathrm{Zn}\left(\mathrm{CH}_{3} \times \mathrm{COO}\right)_{2} \times 2 \mathrm{H}_{2} \mathrm{O}$ used to prepare Carrez solutions were provided by POCH (Gliwice, Poland). Solid phase extraction cartridges Cleanert C18-SPE $500 \mathrm{mg} / 6 \mathrm{~mL}$ were purchased from Agela Technologies (Wilmington, DE, USA) and HPLC membrane filter $(13 \mathrm{~mm}, 0.45 \mu \mathrm{m}$ PTFE) was supplied by Carl Roth (Karlsruhe, Germany).

\section{Bee pollen samples}

The research material consisted of fresh bee pollen samples $(n=15)$ collected in 2011-2014 at an apiary of the Faculty of Beekeeping Technology of the Apiculture Department, Research Institute of Horticulture and donated by Polish beekeepers cooperating in the study. Before the HPLC analysis, samples were subjected to melissopalynological analyses to determine their botanical origin according to the protocols described in studies by Warakomska $(1962,1985)$ and Warakomska \& Masierowska (1992). According to the International Honey Commission's proposed requirements (Campos et al., 2008) for monofloral bee pollen (the major taxon is present at minimum $80 \%$ ), all samples used in this study were classified as multifloral bee pollen. Samples were stored at about $-20^{\circ} \mathrm{C}$ until further analysis. 


\section{Sample preparation}

The homogenized bee pollen sample $(5 \pm 0.001 \mathrm{~g}$ ) was mixed with $48 \mathrm{~mL}$ of acidified water (deionized water with $1 \%$ addition of formic acid), $1 \mathrm{~mL}$ of Carrez solution I and $1 \mathrm{~mL}$ of Carrez solution II in a mechanical shaker at in $25^{\circ} \mathrm{C}$ for $30 \mathrm{~min}$. The bee pollen suspension was then filtered through filter paper with medium wide pores. The filtrate $(10 \mathrm{~mL})$ was loaded onto the Cleanert C18-SPE $(500 \mathrm{mg} / 6 \mathrm{~mL})$ cartridge column, which was previously activated with $6 \mathrm{~mL}$ of methanol, followed by $6 \mathrm{~mL}$ of acidified water. The cartridge was washed with $6 \mathrm{~mL}$ of acidified water, and phenolic compounds were eluted with $6 \mathrm{~mL}$ of methanol (in 3 portions of $2 \mathrm{~mL}$ ). Finally, the eluate (phenolic fraction) was collected into a 10-mL flask, which was filled to a certain volume with methanol. The solution of extract was filtered through a PTFE membrane filter and then injected into the HPLC-DAD system for chromatography analysis.

\section{HPLC-DAD analysis of phenolic compounds}

The Shimadzu HPLC-DAD system (Shimadzu, Kyoto, Japan) consisting of a degasser (DGU-14A), a binary pump (LC-10AT VP), an auto sampler (SIL-10AD VP), a column oven (CTO-10A VP), a diode array detector (SPD-M20A Prominence) and a system controller (SCL-10VP) was used to analyse phenolic compounds in bee pollen loads. Chromatographic separation was performed on a Bionacom STR column ( $2.5 \mu, 3 \times 100 \mathrm{~mm})$, using a gradient program with two solvent systems (A - water with $1 \%$ addition of formic acid, B - methanol) at a constant flow of $1.0 \mathrm{~mL} / \mathrm{min}$. Conditions were initially $16 \% \mathrm{~B}$, then 0.01 36.00 min changed to $90 \% \mathrm{~B} ; 36.00-37.00 \mathrm{~min}$ from $90 \%$ to $16 \% \mathrm{~B}$ and $37.00-46.00 \mathrm{~min}$ at $16 \% \mathrm{~B}$. The column temperature was maintained at $40^{\circ} \mathrm{C}$, and injection volume was $5 \mu \mathrm{L}$.

Chromatograms of phenolic compounds were plotted at $320 \mathrm{~nm}$ and the spectral data for all peaks were accumulated in the range of 190 - $400 \mathrm{~nm}$ using DAD. The obtained chromatograms and spectra were processed with the CLASS-VP v. 7.0 Chromatography Software (Shimadzu, Deutschland $\mathrm{GmbH}$ ). The compounds were identified by comparing their retention times and spectra with reference standards. Quantitative analysis of phenols was performed using the external standard method.

\section{Assay validation}

For quantitative determination of phenolic compounds in bee pollen with HPLC-DAD, such basic parameters of validation as linearity, repeatability, within-laboratory reproducibility, and recovery were determined. Linearity was determined in a concentration range from 2.5 to $10.0 \mathrm{mg} / \mathrm{L}$. Repeatability and within-laboratory reproducibility were determined based on variability coefficients calculated for the content of individual phenols as well as for total phenolic content in bee pollen.

Two solutions of phenolic standard with a concentration of $2.0 \mathrm{mg} / \mathrm{L}$ were injected into the chromatographic column to determine the recovery of phenolic compounds. One solution was extracted on SPE columns. All steps of the SPE procedure were the same as described above for the bee pollen samples except for the volume of phenolic standard loaded onto the SPE column ( $1 \mathrm{~mL}$ of solution with c $=20.0 \mathrm{mg} / \mathrm{L}$ ). The second solution was prepared through the dilution of the basic standard solution ( $c=1.0 \mathrm{mg} / \mathrm{L}$ ) in methanol to obtain the same concentration ( $2.0 \mathrm{mg} / \mathrm{L})$ as after the extraction with the SPE. Both standard solutions were subjected to chromatographic analysis, and the contents of individual phenolic compounds were calculated. The recovery for each compound determined after SPE extraction was calculated from a ratio referring to the contents of individual phenols in the solution obtained without the SPE. The content of a specific phenolic compound in the solution obtained without the SPE was assumed to be $100 \%$.

\section{RESULTS}

Analysis of phenolic compounds in bee pollen Satisfactory separation using HPLC-DAD was obtained for a mixture of thirteen standards: vanillin, caffeic acid, p-coumaric acid, salicylic acids, and flavonoids: rutin, hesperetin, quercetin, pinocembrin, apigenin, kaempferol, isorhamnetin, chrysin, and acacetin (Fig. 1.). 


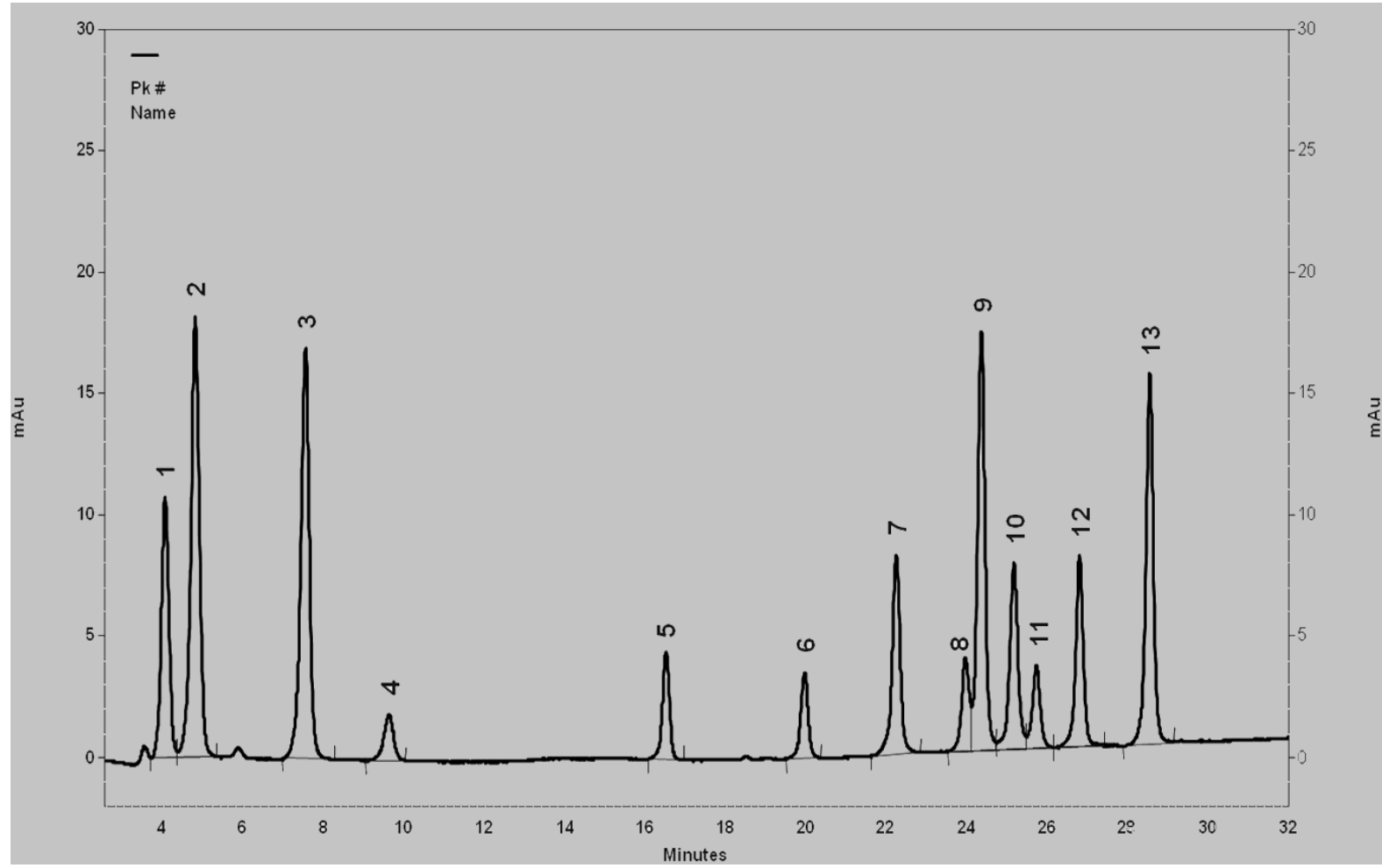

Fig. 1. HPLC-DAD chromatogram of phenolic compounds in the standard mixture: 1 . vanillin; 2. caffeic acid; 3. p-coumaric acid; 4. salicylic acid; 5 . rutin; 6 . hesperetin; 7. quercetin; 8 . pinocembrin; 9. apigenin; 10. kaempferol; 11. isorhamnetin; 12. chrysin; 13. acacetin

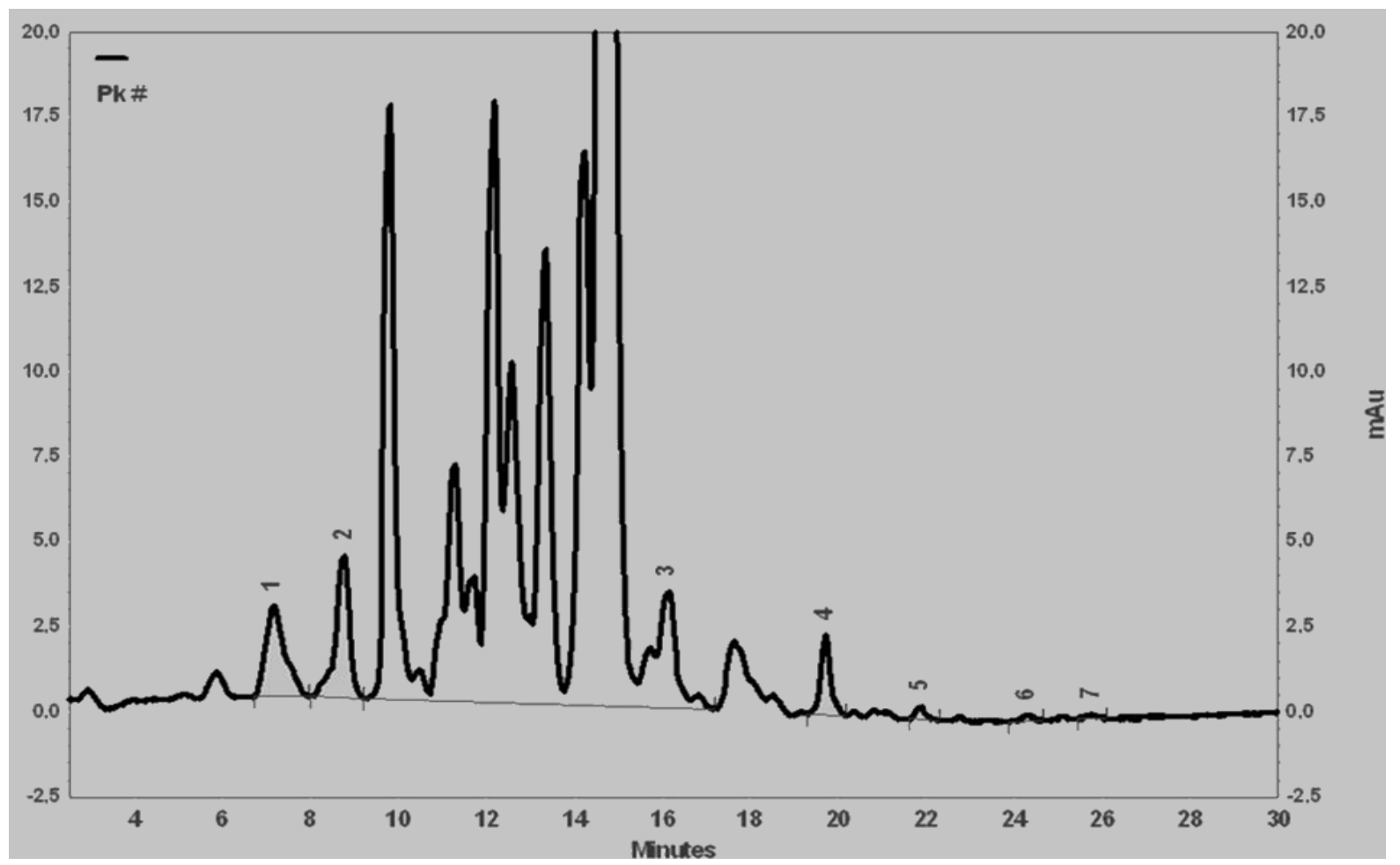

Fig. 2. HPLC-DAD chromatogram of phenolic compounds identified in a bee pollen sample: 1. p-coumaric acid; 2 . salicylic acid 3. rutin; 4. hesperetin; 5 . quercetin; 6 . apigenin; 7. isorhamnetin 
Table 1

Contents (mg/100 g) of phenolic compounds in bee pollen loads

\begin{tabular}{ccccc}
\hline Phenolic compound & $\begin{array}{c}\text { No. of } \\
\text { samples }\end{array}$ & Min - Max & Mean \pm SD & CV (\%) \\
\hline Vanilin & 5 & $0.070-0.230$ & $0.017 \pm 0.01$ & 35.9 \\
Caffeic acid & 2 & $0.004-0.036$ & 0.020 & - \\
P -Coumaric acid & 15 & $0.014-0.224$ & $0.077 \pm 0.06$ & 72.6 \\
Salicylic acid & 15 & $0.119-2.570$ & $1.113 \pm 0.76$ & 68.3 \\
Rutin & 15 & $0.202-5.341$ & $1.192 \pm 1.36$ & 114.1 \\
Hesperetin & 15 & $0.014-0.828$ & $0.256 \pm 0.25$ & 98.7 \\
Quercetin & 12 & $0.008-0.325$ & $0.075 \pm 0.09$ & 117.1 \\
Pinocembrin & 5 & $0.014-0.052$ & $0.025 \pm 0.02$ & 62.6 \\
Apigenin & 15 & $0.003-0.023$ & $0.011 \pm 0.01$ & 51.6 \\
Kaempferol & 10 & $0.005-0.024$ & $0.010 \pm 0.01$ & 59.0 \\
Isorhamnetin & 4 & $0.006-0.015$ & 0.011 & - \\
Chrysin & 2 & $0.007-0.008$ & 0.008 & - \\
Acacetin & 2 & $0.011-0.013$ & 0.012 & - \\
Total & 15 & $0.653-5.966$ & $2.737 \pm 1.67$ & 59.4 \\
\hline
\end{tabular}

*Number of bee pollen samples in which a given phenolic compound was identified

An example of chromatogram of phenolic compounds in bee pollen loads is presented in Fig. 2. The results of the analysis of phenolic compounds in bee pollen samples are collected in Table 1. The following phenols were identified in all analysed samples ( $n=15)$ : $p$-coumaric acid (0.014 - $0.224 \mathrm{mg} / 100 \mathrm{~g})$, salicylic acid $(0.119$ $2.570 \mathrm{mg} / 100 \mathrm{~g})$, rutin $(0.202-5.341 \mathrm{mg} / 100 \mathrm{~g})$, hesperetin (0.014 - $0.828 \mathrm{mg} / 100 \mathrm{~g})$, and apigenin $(0.003-0.023 \mathrm{mg} / 100 \mathrm{~g})$, whereas caffeic acid (0.004 - $0.036 \mathrm{mg} / 100 \mathrm{~g})$, chrysin (0.007 - 0.008 mg/100g) and acacetin (0.011 - $0.013 \mathrm{mg} / 100 \mathrm{~g}$ ) were found just in two samples (Tab. 1). The highest average values were determined for rutin (1.192 mg/100 g) and salicylic acid $(1.113 \mathrm{mg} / 100 \mathrm{~g})$, and the lowest averaged contents were determined for chrysin (0.008 mg/100 g), kaempferol (0.010 mg/100 g), apigenin (0.011 g/100 g), isorhamnetin $(0.011 \mathrm{~g} / 100 \mathrm{~g})$, and acacetin $(0.012 \mathrm{mg} / 100 \mathrm{~g})$.
Total content of phenolic compounds ranged from 0.653 to $5.966 \mathrm{mg} / 100 \mathrm{~g}$ (on average $2.737 \mathrm{mg} / 100 \mathrm{~g}$ ). The bee pollen samples showed a high variability of qualitative and quantitative composition for phenolic compounds (Tab.1). The highest variability (CV>100\%) was observed for the contents of rutin and quercetin and the lowest variability (CV=35.9\%) was noted for vanillin content but was identified only in five samples. The coefficient of variation (CV) for the total content of phenolic compounds amounted to $59.4 \%$.

\section{HPLC-DAD method validation}

The results of basic validation parameters are collected in Table 2. For all of the identified phenolic compounds (except salicylic acid), the coefficients of linear correlation were $\geq 0.997$. The average coefficient of variation for total content of phenols under the conditions of re- 
Results of validation (mean values) of the HPLC-DAD method

Table 2

\begin{tabular}{|c|c|c|c|c|}
\hline \multirow[b]{2}{*}{ Phenolic compound } & \multirow{2}{*}{$\begin{array}{l}\text { Correlation } \\
\text { coefficient* } \\
\quad(n=3)\end{array}$} & \multicolumn{2}{|c|}{ Coefficient of variation (\%) } & \multirow{2}{*}{$\begin{array}{l}\text { Recovery (\%) } \\
\quad(n=2)\end{array}$} \\
\hline & & $\begin{array}{l}\text { Repeatability } \\
\quad(n=3)\end{array}$ & $\begin{array}{l}\text { Reproducibility } \\
\qquad(n=5)\end{array}$ & \\
\hline Vanilin & 0.9967 & n.d. ${ }^{\star \star}$ & n.d.** & 110.9 \\
\hline Caffeic acid & 0.9982 & n.d. ${ }^{\star \star}$ & n.d.** & 107.1 \\
\hline p-Coumaric acid & 0.9995 & 2.4 & 4.8 & 107.9 \\
\hline Salicylic acid & 0.9194 & 2.4 & 6.6 & 103.6 \\
\hline Rutin & 0.9989 & 2.1 & 4.9 & 110.3 \\
\hline Hesperetin & 0.9991 & 0.6 & 10.8 & 136.7 \\
\hline Quercetin & 0.9980 & 3.6 & 11.0 & 106.5 \\
\hline Pinocembrin & 0.9969 & 4.7 & 16.1 & 112.5 \\
\hline Apigenin & 0.9978 & 6.7 & 7.6 & 114.7 \\
\hline Kaemferol & 0.9992 & 8.5 & 10.3 & 118.0 \\
\hline Isorhamnetin & 0.9978 & 9.4 & 11.7 & 100.8 \\
\hline Chrysin & 0.9992 & n.d. ${ }^{* *}$ & n.d.** & 114.0 \\
\hline Acacetin & 0.9981 & n.d. ${ }^{\star \star}$ & n.d. ${ }^{* *}$ & 124.3 \\
\hline Total & - & 1.7 & 5.1 & 112.1 \\
\hline
\end{tabular}

* Correlation coefficients calculated in concentration range from 2.5 to $10.0 \mathrm{mg} / \mathrm{L}$

** not detected

peatability and within-laboratory reproducibility were $1.7 \%$ and $5.1 \%$, respectively. No coefficient of variation of repeatability calculated for an individual phenolic compound exceeded $10 \%$, whereas the highest coefficients of variation of within-laboratory reproducibility were determined for pinocembrin (16.1\%), isorhamnetin $(11.7 \%)$, and quercetin (11.0\%). The recovery for total phenols as well as for individual compounds was over $100 \%$ (Tab. 2).

\section{DISCUSSION}

The composition of phenolic compounds in bee pollen collected under Polish pollen flow conditions has not been well recognised. Rzepecka-Stojko et al. $(2010,2012)$ showed that their content depended on the method extraction of these compounds and bee pollen extract storage. These studies used the spectrophotometric method with Folin-Ciocalteu reagent to determine phenolic compounds in bee pollen extracts, but only total phenolic content was determined as it was impossible to identify individual compounds with this method. Leja et al. (2007) determined the total content of phenolic compounds in pollen loads in the context of their influence on the antioxidative properties of bee pollen. This paper's authors stressed the necessity of further studies toward the separation of phenolic compounds present in pollen loads in order to establish the influence of individual compounds on the antiradical properties of bee pollen. 
The HPLC-DAD method presented in this paper has been used for the first time in Poland for qualitative and quantitative determination of phenolic compounds in bee pollen loads. Satisfactory chromatographic separation of vanillin, some phenolic acids (caffeic, p-coumaric and salicylic) and flavonoids (rutin, hesperetin, quercetin, pinocembrin, apigenin, kaempferol, isorhamnetin, chrysin and acacetin) was obtained on a Bionacom STR column, using a gradient program with two solvent systems. Phenolic compounds were extracted from bee pollen loads with the use of Cleanert C18-SPE cartridges. The compounds were identified by comparing their retention times and spectra with reference standards. Quantitative analysis of phenols was done using the external standard method. Satisfactory coefficients of correlation ( $\geq 0.997)$ were obtained for all the identified phenolic compounds (except for the salicylic acid). Moreover, the method reported here showed satisfactory repeatability and withinlaboratory reproducibility.

The HPLC-DAD technique has been recently used in Poland for the analysis, but only qualitative, of phenolic compounds in order to identify the botanical origin of Polish monofloral honeys (Kuś et al., 2014). Similarly, in the majority of foreign papers concerning phenolic compounds in bee products, including bee pollen, the HPLC-DAD was used only for their identification (Markham \& Campos, 1996; Campos et al., 1997; Campos, Webby, \& Markham, 2002; Almaraz-Abarca et al., 2004, 2007, 2008; Freire et al., 2012). However, qualitative analysis of phenolic compounds is important not only for the characterization of bee pollen chemical composition but also because the chromatographic profile (the so-called fingerprint) of phenolic compounds is characteristic for a certain taxon and can be used to determine the botanical origin of bee pollen loads (Campos et al., 1997; Campos, Webby, \& Markham, 2002; AlmarazAbarca et al., 2004, 2007, 2008; Freire et al., 2012). According to some authors and the International Honey Commission, the identification of bee pollen's botanical origin based on the chromatographic profile of phenolic compounds is more precise than the traditional microscopic method (Campos et al., 1997, 2008; AlmarazAbarca et al., 2007).

The analysed samples of bee pollen loads presented different qualitative and quantitative compositions of phenolic compounds. P-coumaric acid, salicylic acid, and flavonoids: rutin, hesperetin, and apigenin were found in each sample, but nevertheless the contents of these compounds significantly differed. Variability coefficients calculated for contents of these compounds ranged from $51.6 \%$ (for the apigenin) to $114.1 \%$ (for the rutin). Other analysed compounds were identified only in some samples: quercetin in 12, kaempferol in 10 , vanilin and pinocembrin in 5 , isorhamnetin in 4, and caffeic acid, chrysin, and acacetin only in 2. The noted differences in the composition of phenolic compounds resulted from the diversity of plant species from which the pollen was collected. Based on the melissopalynological analysis, all of the tested samples of pollen loads were classified to multifloral pollen loads which is why our results did not allow the determination of markers - phenolic compounds characteristic for Polish monofloral bee pollen. The composition of phenolic compounds in bee pollen loads, similarly as in the case of other chemical compounds of bee pollen strictly depends on botanical origin, which was also presented by other authors (Almeida-Muradian et al., 2005, Almaraz-Abarca et al., 2008; Mărghitaș et al., 2009). It is difficult to compare our results with those of other authors due to different botanical and geographical origin of analysed bee pollen loads (Markham \& Campos, 1996; Campos et al., 1997; Campos, Webby, \& Markham, 2002; Almaraz-Abarca et al., 2004, 2007, 2008; Freire et al., 2012; Lv et al., 2015). Moreover, authors of those studies determined such phenolic compounds as aglycones (complexes with sugars). In our studies, the SPE technique with C18 columns was used to isolate the phenolic compounds from the bee pollen loads at the stage of sample preparation for chromatographic analyses. The SPE technique with the C18 column was previously tested in Poland in the extraction of phenolic compounds from honey (Michalkiewicz, Biesaga, \& Pyrzynska, 2008). However, the extraction of 
phenolic compounds from bee pollen loads with the SPE technique on a octadecyl sorbent (C18) was also conducted by Ulusoy \& Kolayli (2013). The total phenolic content was determined in a number of papers concerning the antioxidative properties of bee pollen (Almaraz-Abarca et al., 2004, 2007; Leja et al., 2007; Carpes et al., 2007, 2009; LeBlanc et al., 2009; Mărghitaș et al., 2009; Graikou et al., 2011; Freire et al., 2012; Prelipcean, 2012; Ulusoy \& Kolayli, 2013). Most of these studies used the common colorimetric method with the Folin-Ciocalteu reagent for the quantitative analysis of polyphenols (Carpes et al., 2007, 2009; LeBlanc et al., 2009; Mărghitaș et al., 2009; Graikou et al., 2011; Freire et al., 2012; Prelipcean, 2012; Ulusoy \& Kolayli, 2013). As mentioned, the Folin-Ciocalteu method allows only the determination of the total phenolic content so it is impossible to compare our results concerning the contents of individual phenolic compounds with the results presented in the above-mentioned papers. It is also difficult to compare our results on the total phenolic content with other authors' results due to the little selectivity of the Folin-Ciocalteu method (Martha-Estrella, Niokhor, \& Stevanovic, 2008). Different non-phenolic compounds, such as reducing sugars, can cause interference in this method and overestimate analysis' results. Although the HPLC method is more selective from the previously mentioned one, we were unable to identify all of the phenolic compounds occurring in bee pollen, so our results for the total phenolic content were much lower. Similarly, Ulusoy \& Kolayli (2013) obtained lower results for the total phenolic content using the HPLC method (from 502.94 to $2660.60 \mu \mathrm{g} / 100 \mathrm{~g}$ ) in comparison to the Folin-Ciocalteu method (from 44.07 to $124.10 \mathrm{mg} / \mathrm{g}$ ) and it needs to be stressed that total phenolic contents were determined in the same samples using the two methods. Discrepancies between our and other authors' results arose not only from using different methods but mainly from differences in the composition of phenolic compounds connected to botanical and geographical origin of pollen samples. Leja et al. (2007) proved the high variability of Polish pollen's antioxidative properties and total phenolic content - the highest (8243 $\mathrm{mg} / 100 \mathrm{~g})$ and the lowest $(1293 \mathrm{mg} / 100 \mathrm{~g})$ in the pollen of Pyrus communis and Zea mays, respectively.

The results of our studies met other authors' expectations which, due to the high variability of bee pollen composition, indicated the necessity of further studies on the precise determination of phenolic compounds (Кroyer \& Hegedus, 2001; Leja et al., 2007; Carpes et al., 2009; Mărghitaș et al., 2009). The HPLC-DAD method that we elaborated allows for the identification of phenolic compounds in bee pollen. It can be further employed to characterise the composition of polyphenols in bee pollen collected under pollen flow conditions of Poland, but such studies should be conducted on samples of monofloral pollen. To assess the usefulness of the HPLC-DAD method for quantitative analysis of polyphenols, its validation should be extended. It is necessary to test the linearity in lower ranges in order to both determine the method's working range and limit of quantification and to validate its repeatability and reproducibility for the determination of chrysin and acacetin. Although the quantitative method requires further evaluation, it needs to be stressed that we were one of the few to use the HPLC-DAD technique to analyse phenolic compounds in bee pollen quantitatively. Only Serra Bonhevi, Soliva Torrentó, \& Centelles Lorente (2001), Šarić et al. (2009), and Ulusoy \& Kolayli (2013) had used this method for the same purpose.

The HPLC-DAD method as elaborated by us can be further used for the quality control of bee pollen because, according to some authors and the International Honey Commission, the composition of phenolic compounds can be an indicator of bee pollen quality which should be controlled during the process of collection and storage (Campos et al., 1997; Campos et al., 2008).

\section{ACKNOWLEDGEMENTS}

The authors are grateful to their colleagues from the Faculty of Beekeeping Technology of the Apiculture Department, Research Institute as well as to the individual beekeepers for 


\section{supplying the bee pollen samples.}

\section{REFERENCES}

Almaraz-Abarca, N., Campos, M.G., Ávila-Reyes, J.A., Naranjo-jimenèz, N., Herrera-Corral, J., \& GonzálezValdez, L.S. (2004). Variability of antioxidant activity among honeybee-collected pollen of different botanical origin. Interciencia, 29(10), 574-578.

Almaraz-Abarca, N., Campos, M.G., Ávila-Reyes, J.A., Naranjo-Jimenèz, N., Herrera-Corral, J., \& GonzálezValdez, L.S. (2007). Antioxidant activity of polyphenolic extract of monofloral honeybee-collected pollen from mesquite (Prosopis juliflora, Leguminosae). Journal of Food Composition and Analysis, 20, 119124. http://doi.org/10.1016/j.jfca.2006.08.001

Almaraz-Abarca, N., Campos, M.G, Delagado-Alvarado, E.A., Ávila-Reyes, J.A., Herrera-Corral, J., GonzálezValdez, L.S., ... Uribe-Soto, J.N. (2008). Pollen Flavonoid/Phenolic Acid Composition of Four Species of Cactaceae and its Taxonomic Significance. American Journal of Agricultural and Biological Sciences, 3(3), 534-543.

Almeida-Muradian, L.B., Pamplona, L.C., Coimbra, S., \& Barth, O.M. (2005). Chemical composition and botanical evaluation of dried bee pollen pellets. Journal of Food Composition and Analysis, 18, 105-111. http://doi.org/10.1016/j.jfca.2003.10.008

Campos, M., Markham, K.R, Mitchel, K.A., \& da Cunha, A.P. (1997). An Approach to the Characterization of Bee Pollens via their Flavonoid/Phenolic Profiles. Phytochemical Analysis, 8, 181-185.

Campos, M.G, Webby, R.S., \& Markham, K.R. (2002). The Unique Occurrence of the Flavone Aglycone Tricetin in Myrtaceae Pollen. Zeitschrift für Naturforschung, 57(9-10), 944-946.

Campos, M.G, Bogdanov, S., de Almeida-Muradian, L.B., Szczesna T., Mancebo, Y., Frigerio, C., Ferreira, $F$. (2008). Pollen composition and standarisation of analytical methods. Journal of Apicultural Research and Bee World, 472), 156-163.
Carpes, S.T., Mourao, G.B., de Alencar, S.M., \& Masson, M.L. (2009). Chemical composition and free radical scavenging activity of Apis melliferabee pollen from Southern Brazil. Brazilian Journal of Food Technology, 12(3), 220-229. http://doi.org/10.4260/ BJFT2009800900016

Carpes, S.T., Begnini, R., de Alencar, S. M., \& Masson, M.L. (2007). Study of preparations of bee pollen extracts, antioxidant and antibacterial activity. Ciência e Agrotecnología, 37(6), 1818-1825, http:/doi. org/10.1590/\$1413-70542007000600032

Cook, N.C, \& Samman, S. (1996). Flavonoids-Chemistry, metabolism, cadioprotective effects, and dietary sources. Nutritional Biochemistry, 72), 66-76.

Freire, K.R.L., Lins, A.C.S., Dórea, M.C., Santos, F.A.R., Camara, C.A., \& Silva, T.M.S. (2012). Palynological Origin, Phenolic Content, and Antioxidant Properties of Honeybee-Collected Pollen from Bahia, Brazil. Molecules, 17, 1652-1664, http://doi.org/10.3390/molecules17021652

Graikou, K., Kapeta, S., Aligiannis, N., Sotiroudis, G., Chondrogianni N., Gonos, E., Chinou, I. (2011). Chemical analysis of Greek pollen - Antioxidant, antimicrobial and proteasome activation properties. Chemistry Central Journal, 5(1):33, 1-9. http://doi. org/10.1186/1752-153X-5-33

Kroyer, G., \& Hegedus, N. (2001). Evaluation of bioactive properties of pollen extracts as functional dietary food suplement. Innovative Food Science \& Emerging Technologies, 2, 171-174.

KuŚ, P.M., Congiu, F., Teper, D., Sroka, Z., Jerković, I. (2014). Antioxidant activity, color characteristics, total phenol content and general HPLC fingerprints of six Polish unifloral honey types. LWT - Food Science and Technology, 55, 124-130. http://doi. org/10.1016/j.lwt.2013.09.016

LeBlanck, W.B., Davis, O.K., Boue, S., Delucca, A. Deeby, T. (2009). Antioxidant activity of Sonoran Desert bee pollen. Food Chemistry, 715, 1299-1305. http://doi.org/10.1016/j.foodchem.2009.01.055 
Leja, M., Mareczek, A., Wyżgolik, G., Klepacz-Baniak, J., Czekońska, K. (2007). Antioxidative properties of bee pollen in selected plant species. Food Chemistry, 100, 237-240. http://doi.org/10.1016/j.foodchem.2005.09.047

Lv, H., Wang, X., He, Y., Wang, H., Suo, Y. (2015). Identification and quantification of flavonoids aglycones in rape bee pollen from Qinghai-Tibetan Plateau by HPLC-APCI/MS. Journal of Food Composition and Analysis, 38, 49-54, http://doi.org/10.1016/j. jfca.2014.10.011

Mărghitaș, L.A., Stanciu, O.G., Dezmirean, D.S., Bobiș, O., Popescu, O., Bogdanov, S., Campos, M.G. (2009). In vitro antioxidant capacity of honeybee-collected pollen of selected floral origin harvested from Romania. Food Chemistry, 775, 879-883. http://doi. org/10.1016/j.foodchem.2009.01.014

Markham, K.R., \& Campos, M.G. (1996). 7-and 8-0methylherbacetin-3- 0-sophorosides from bee pollens and some structure/activity observations. Phytochemistry, 43(4), 763-767.

Martha-Estrella, G.P., Niokhor, D.P., \& Stevanovic, T. (2008). Comparative study of antioxidant capacity of yellow birch twigs extracts at ambient and high temperatures. Food Chemistry, 107, 344-351. https://doi.org/10.1016/j.foodchem.2007.08.026

Michalkiewicz, A., Biesaga, M., \& Pyrzynska, K. (2008). Solid-phase extraction procedure for determination of phenolic AIDS and some flavonols in honey. Journal of Chromatography A, 1187, 18-24. http://doi. org/10.1016/j.chroma.2008.02.001

Omnia, M.A., Nabila M.A., \& Nadia, R.R. (2014). Biochemical effects of propolis and bee pollen in experimentally - induced hyperammonemia in rats. Benha Veterinary Medical Journal, 271), 8-24.

Prelipcean, A.A. (2012). The dynamics of total polyphenols, flavonoids and antioxidant activity of beepollen collected from Moldavia area, Romania. Cercetări Agronomice în Moldova, XLV, 7(149), 81-91.

Rzepecka-Stojko, A., Maciejewska-Paszek, I., Stec,
M., Kurzeja, E., Kęska, A., Pawłowska-Góral, K. (2010). Wpływ metody ekstrakcji na pozyskiwanie związków polifenolowych z obnóży pszczelich [The influence of extraction method on obtaining polyphenolic compound from bee pollen]. Farmaceutyczny Przegląd Naukowy, 7, 38-41.

Rzepecka-Stojko, A., Stec, M., Kurzeja, E., Gawrońska, E., Pawłowska-Góral, K. (2012). The Effects of Storage of Bee Pollen Extracts on Polyphenol Content. Polish Journal of Environmental Studies, 27(4), 10071011.

Šarić, A., Balog, T., Sobočanec, S., Kušić, B., Šverko, V., Rusak, G.,... Marotti, T. (2009). Antioxidant effects of flavonoid from Croatian Cystus incanus L. rich bee pollen. Food and Chemical Toxicology, 47, 547-554. http://doi.org/10.1016/j.fct.2008.12.007

Serra Bonhevi, J., Soliva Torrentó, M., \& Centelles Lorente, E. (2001). Evaluation of Polyphenolic and Flavonoid Compounds in Honeybee-Collected Pollen Produced in Spain. Journal of Agricultural and Food Chemistry, 49(4), 1848-1853. http://doi.org/10.1021/ jf0012300

Ulusoy, E., \& Kolayli, S. (2013). Phenolic composition and antioxidant properties of Anzer bee pollen. Journal of Food Biochemistry, 38, 73-82.

Warakomska, Z. (1962). Badania nad zbiorem pyłku przez pszczołę miodną (Apis mellifical.) w rolniczych okolicach Polski. Annales UMCS, Sec. E, 17,67-106.

Warakomska, Z. (1985). Obraz pyłkowy miodów i pierzgi Kotliny Jeleniogórskiej. Pszczelnicze Zeszyty Naukowe, 29, 253-263.

Warakomska, Z. \& Masierowska, M. (1992). Pollen food of honeybee in the conditions of a gardening farm. Natural Resourses of Wild Bees in Poland. Pedagogical University, Bydgoszcz, 119-132.

Yao, L.H., Jiang, Y.M., Shi, J., Tomás-Barberán, F.A., Datta, N., Singanusong, R., Chen, S.S. (2004). Flavonoids in Food and Their Health Benefits. Plant Foods for Human Nutrition, 59, 113-122. 